\title{
Growth And Oil Futures Prices In Developing Countries
}

Salah Abosedra, (E-mail: salaheddin.abosedra@ lau.edu.lb), Lebanese American University, Beirut, Lebanon Sajal Ghosh, (E-mail: sghosh@mdi.ac.in), Management Development Institute, Gurgaon, India

\begin{abstract}
This paper examines cointegration and causality between oil prices and economic growth for the oil importing developing countries of Turkey, India, Pakistan, The Philippines and Korea. The study finds the absence of cointegrating relationship between oil prices and economic activity but the existence of unidirectional short-run causality running from oil prices to economic growths for The Philippines and Pakistan. Unidirectional causality is also found to exist from six and nine month futures prices to economic growth for India and Turkey in a bivariate vector autoregression framework. The study fails to establish causal relationship between oil prices and economic growth for Korea, while for India and Turkey, non-causality has been established between oil spot price and economic growth. Hence, our results may suggest that oil futures markets will have more of a role to play in the economy as these markets mature and or as oil prices continue to increase.
\end{abstract}

\section{INTRODUCTION}

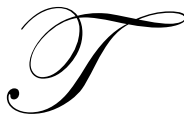

he question of how increases in oil price influence economic growth of oil consuming economies has attracted a great deal of research activities, especially since the publication of the seminal work of James Hamilton (1983). Much of the research in this area has focused on studying the above mentioned issue on the U.S. economy and other developed economies including Japan, Germany, UK, and Canada, [Mork \& Hall (1980), Bruno \& Sachs (1981), Rasche and Tatom (1981), Bruno and Sachs (1982), Darby (1982), Harkness (1982), Burbidge \& Harrison (1984), Gisser \& Goodwin (1986), Mork (1989), Mork et al. (1994), JimenezRodriguez (2004) and Jimenez- Lee et al (1995), Ferderer (1996), Hamilton (1996), Bjørnland (2000) Hamilton (2003), Rodriguez \& Sanchez (2005), among others].

In contrast to this research, empirical work focusing on the impacts on developing economies has been relatively limited [Hwang \& Gum (1992), Asafu-Adjaye (2000), Yang (2000), two reports by the IMF and IEA (2000 \& 2004), Fatai, Oxley \& Scrimgeous (2004), Bacon, Streifel \& Burns (2005), among others]. This neglect is surprising for at least three reasons. First, demand for oil in developed economies has decelerated over the last 30 years or so due to the decease in oil intensity in these economies, which resulted primarily from fuel saving technical changes. However, this oil intensity increased in most developing countries (Figure 1), due to the expansion of their manufacturing sector, which is still energy intensive; the increase in vehicle ownership, and the continuous shift to modern fuels from traditional ones. Second, with rapid growth expected to continue in China, India, and other developing countries over the coming 20 years, examining this issue has a practical and timely value for economic planners in these countries. Third, the majority of developing countries are net oil importers.

This paper, therefore, will extend the empirical literature by examining cointegration and causality between futures oil prices and economic growth for the oil importing developing countries of Turkey, India, Pakistan, The Philippines, and Korea. The remainder of this paper is organized as follows. In section 2, we discuss the data sources, and present the econometric methodology used in the analysis. Results from testing our null hypothesis of a unit root against the alternative hypothesis of stationarity and the Granger causality results for our sample countries are presented in Section 3. The final section includes our concluding remarks. 
Figure 1 - Oil Intensity Of Production In Developing Countries And In The OECD Area

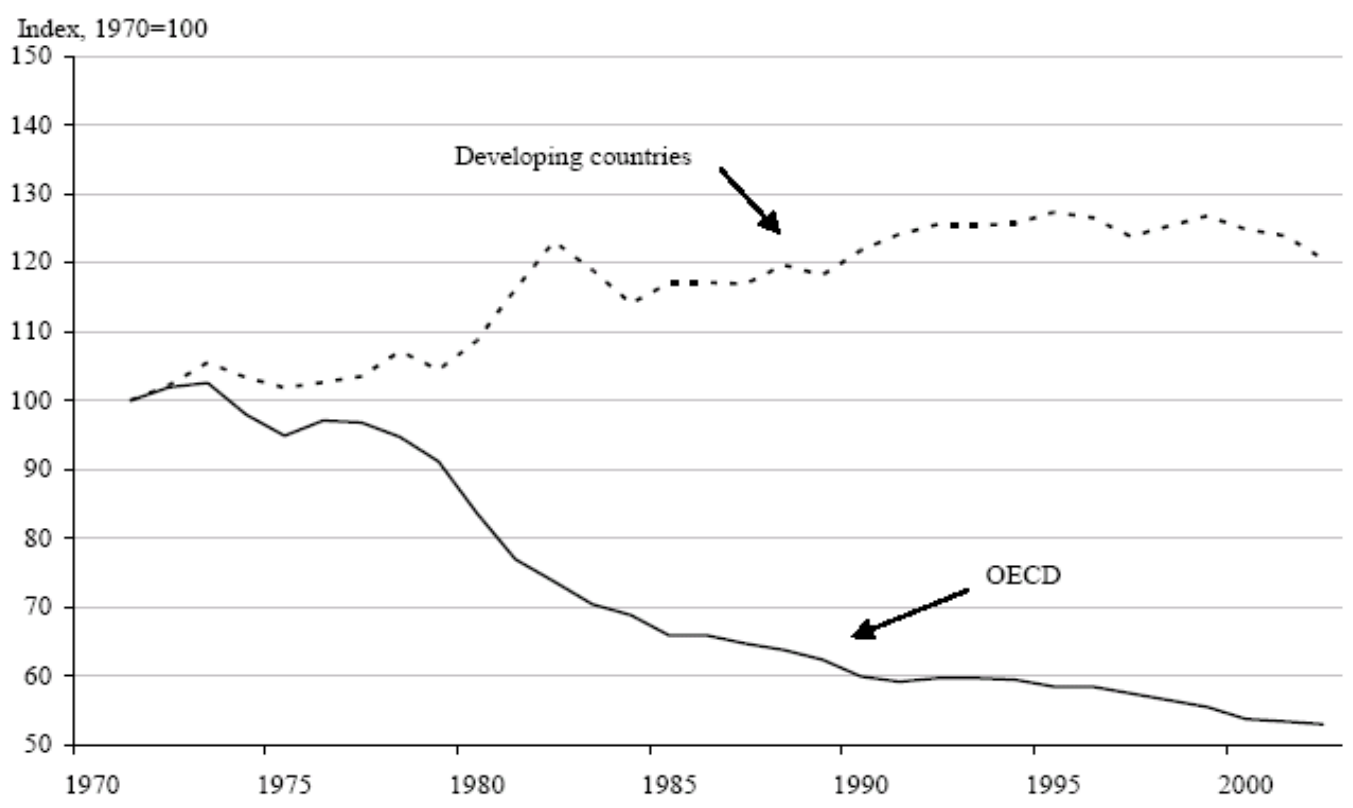

Note: Oil intensity is defined as total primary oil use per unit of output (GDP).

Source: OECD Economic Outlook 76 database and International Energy Agency (from OECD Economic Outlook No. 76)

\section{ECONOMETRIC METHODOLOGY \& DATA DESCRIPTIONS}

If the series $\mathrm{X}$ and $\mathrm{Y}$ are individually integrated of order one, i.e., I (1) and cointegrated then Granger causality tests may use I (1) data because of the super consistency properties of estimation.

$$
\begin{aligned}
& X_{t}=\alpha+\sum_{i=1}^{m} \beta_{i} X_{t-i}+\sum_{j=1}^{n} \gamma_{j} Y_{t-j}+u_{t} \ldots \ldots \ldots \ldots \text { (1) } \\
& Y_{t}=a+\sum_{i=1}^{q} b_{i} Y_{t-i}+\sum_{j=1}^{r} c_{j} X_{t-j}+v_{t} \ldots \ldots \ldots \ldots \text { (2) }
\end{aligned}
$$

Where $\mathrm{u}_{\mathrm{t}}$ and $\mathrm{v}_{\mathrm{t}}$ are zero-mean, serially uncorrelated, random disturbances.

Secondly, Granger causality tests with cointegrated variables may utilize the I (0) data with an error correction term i.e. 


$$
\begin{aligned}
& \Delta X_{t}=\alpha+\sum_{i=1}^{m} \beta_{i} \Lambda X_{t-i}+\sum_{j=1}^{n} \gamma_{j} \Delta Y_{t-j}+\delta E C M_{t-1}+u_{t} \ldots \ldots \ldots \text { (3) } \\
& \Delta Y_{t}=a+\sum_{i=1}^{q} b_{i} \Delta Y_{t-i}+\sum_{j=1}^{r} c_{j} \Delta X_{t-j}+d E C M_{t-1}+v_{t} \ldots \ldots . .(4)
\end{aligned}
$$

Thirdly, if the data are I(1) but not cointegrated, valid Granger type tests require transformation to make them $\mathrm{I}(0)$. So, in this case the equations become

$$
\begin{aligned}
& \Delta X_{t}=\alpha+\sum_{i=1}^{m} \beta_{i} \Delta X_{t-i}+\sum_{j=1}^{n} \gamma_{j} \Delta Y_{t-j}+u_{t} \ldots .(5) \\
& \Delta Y_{t}=a+\sum_{i=1}^{q} b_{i} \Delta Y_{t-i}+\sum_{j=1}^{r} c{ }_{j} \Delta X_{t-j}+v_{t} \ldots \ldots(6)
\end{aligned}
$$

The optimum lag length $\mathrm{m}, \mathrm{n}, \mathrm{q}$ and $\mathrm{r}$ are determined on the basis of Akaike's (AIC) and/or Schwarz Bayesian (SBC) and/or log-likelihood ratio test (LR) Criterion.

Now, for equation (2) and (3), Y Granger causes (GC) X if,

$\mathrm{H}_{0}: \quad \gamma_{1}=\gamma_{2}=\ldots .=\gamma_{\mathrm{n}}=0$ is rejected

Against $\mathrm{H}_{\mathrm{A}}$ : $=$ at least one $\gamma_{\mathrm{j}} \neq 0, \mathrm{j}=1 \ldots \ldots \mathrm{n}$

and $\mathrm{X} \mathrm{GC} \mathrm{Y} \mathrm{if,} \quad \mathrm{H}_{0}: \quad \mathrm{c}_{1}=\mathrm{c}_{2}=\ldots . .=\mathrm{c}_{\mathrm{n}}=0$ is rejected

Against $\mathrm{H}_{\mathrm{A}}$ : $=$ at least one $\mathrm{c}_{\mathrm{j}} \neq 0, \mathrm{j}=1 \ldots \ldots \mathrm{r}$

For equation (4) and (5), $\Delta \mathrm{Y} \mathrm{GC} \Delta \mathrm{X}$ if,

$\mathrm{H}_{0}: \quad \gamma_{1}=\gamma_{2}=\ldots .=\gamma_{\mathrm{n}}=0$ is rejected

Against $\mathrm{H}_{\mathrm{A}}$ : $=$ at least one $\gamma_{\mathrm{j}} \neq 0, \mathrm{j}=1 \ldots \ldots \mathrm{n}$, or $\delta \neq 0$

and $\triangle \mathrm{X} \mathrm{GC} \Delta \mathrm{Y}$ if, $\quad \mathrm{H}_{0}: \quad \mathrm{c}_{1}=\mathrm{c}_{2}=\ldots . .=\mathrm{c}_{\mathrm{n}}=0$ is rejected

Against $\mathrm{H}_{\mathrm{A}}$ : $=$ at least one $\mathrm{c}_{\mathrm{j}} \neq 0, \mathrm{j}=1 \ldots . \mathrm{r}$, or $\mathrm{d} \neq 0$

For equation (6) and (7), $\Delta \mathrm{Y}$ GC $\Delta \mathrm{X}$ if,

$\mathrm{H}_{0}: \quad \gamma_{1}=\gamma_{2}=\ldots . .=\gamma_{\mathrm{n}}=0$ is rejected

Against $\mathrm{H}_{\mathrm{A}}$ : $=$ at least one $\gamma_{\mathrm{j}} \neq 0, \mathrm{j}=1 \ldots \ldots \mathrm{n}$,

and $\Delta \mathrm{X} \mathrm{GC} \Delta \mathrm{Y}$ if, $\quad \mathrm{H}_{0}: \quad \mathrm{c}_{1}=\mathrm{c}_{2}=\ldots . .=\mathrm{c}_{\mathrm{n}}=0$ is rejected

Against $\mathrm{H}_{\mathrm{A}}$ : $=$ at least one $\mathrm{c}_{\mathrm{j}} \neq 0, \mathrm{j}=1 \ldots . \mathrm{r}$,

The tests are conducted on monthly data covering the period January 1985 to January 2005 for India, Turkey, Korea and The Philippines and June 1994 to January 2005 for Pakistan. Data on Index of Industrial Production (IIP), as a proxy to economic growth, have been collected from the International Financial Statistics (IFS) database. Monthly crude prices are WTI (spot, three, six and nine month's futures prices) and are taken from the Energy Information Administration and the New York Mercantile Exchange (NYME). X (i) [i= India (I), Pakistan (Pa), 
Turkey (T), Korea (K) \& The Philippines $(\mathrm{Ph})]$ and $\mathrm{P}(\mathrm{j})[\mathrm{j}=\operatorname{spot}(\mathrm{S}), \mathrm{t}=3(3), \mathrm{t}=6(6), \mathrm{t}=9(9))$ represent IIP and WTI spot and futures prices respectively, after their logarithmic transformation.

\section{EMPIRICAL RESULTS} model:

In the first stage the order of integration of the data is investigated. ADF test is conducted with the following

$\Delta \mathrm{X}_{\mathrm{t}}=\alpha_{0}+(1-\mathrm{k}) \beta \mathrm{t}-(1-\mathrm{k}) \mathrm{X}_{\mathrm{t}-1}+\Sigma \gamma_{\mathrm{j}} \Delta \mathrm{X}_{\mathrm{t}-\mathrm{j}}+\varepsilon_{\mathrm{t}} ; \quad(\mathrm{j}: 1,2, \ldots, \mathrm{p})$ estimated.

Where $X_{t}$ is the underlying variable at time $t, \varepsilon_{t}$ is the error term and $\alpha_{0}, \beta \mathrm{k}$ and $\gamma_{\mathrm{j}}$ are the parameters to be

Table 1 presents the results of unit root tests on the natural logarithms of the levels and the first differences of the variables. On the basis of ADF statistics, the null hypothesis of a unit root cannot be rejected at 5 per cent level of significance. Stationarity is obtained by running the similar test on the first difference of the variables, indicating that all the series are I (1) in nature.

Table 1- Augmented Dickey-Fuller (ADF) unit root Tests

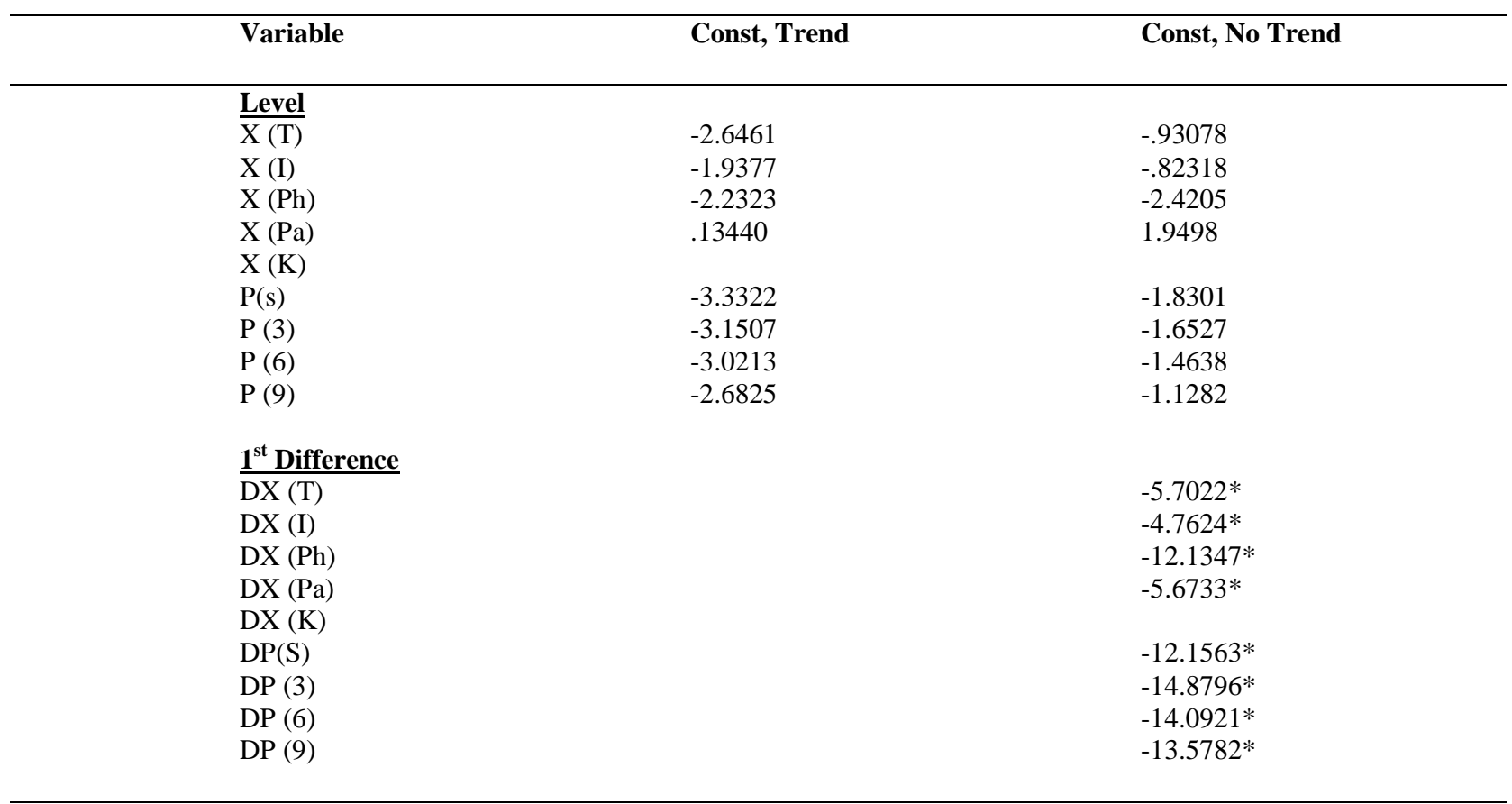

95\% critical value for the ADF statistic (Const, Trend) $=-3.4306$

$95 \%$ critical value for the ADF statistic (Const, No Trend) $=-2.8742$

*represents rejection of null hypothesis at $5 \%$ level of significance

In the second stage, the Johansen maximum likelihood procedure is used to detect cointegration. This provides a unified framework for estimation and testing of cointegrating relations in the context of a VAR error correction model. The cointegration rank, $r$, of the time series was tested using two test statistics. Denoting the number of cointegrating vectors by $r_{0}$, the maximum Eigen value $(\lambda \max )$ test is calculated under the null hypothesis that $r_{0}=r$, against the alternative of $r_{0}>r$. The trace test is calculated under the null hypothesis that $r_{o} \leq r$, against $r_{0}>r$. 
Table 2. Johansen-Juselius Likelihood Cointegration Tests

\begin{tabular}{|c|c|c|c|c|}
\hline Null Alternative & & s & & \\
\hline & $\mathbf{X}(\mathbf{I}) \& \mathbf{P}(\mathbf{S})$ & $\mathbf{X}(\mathbf{I}) \& \mathbf{P}(3)$ & $\mathbf{X}(\mathbf{I}) \& \mathbf{P}(6)$ & $\mathbf{X}(\mathbf{I}) \& \mathbf{P}(\mathbf{9})$ \\
\hline & & & & \\
\hline Trace Tests & & & & \\
\hline$r=0 \quad r=1$ & 12.4144 & 11.5957 & 11.040 & 11.0318 \\
\hline$r<=1 \quad r=2$ & 2.8041 & 2.4522 & 1.8776 & 1.5279 \\
\hline Eigen Value Tests & & & & \\
\hline$r=0 \quad r>=1$ & 15.2184 & 14.0479 & 12.9181 & 12.5597 \\
\hline$r<=1 \quad r=2$ & 2.8041 & 2.4522 & 1.8776 & 1.5279 \\
\hline & & & & \\
\hline$\overline{\text { Trace Tests }}$ & & & & \\
\hline$r=0 \quad r=1$ & 12.1160 & 11.0756 & 10.1566 & 9.8679 \\
\hline$r<=1 \quad r=2$ & 0.82535 & 0.57401 & 0.28520 & 0.14119 \\
\hline Eigen Value Tests & & & & \\
\hline$r=0 \quad r>=1$ & 12.9413 & 11.6496 & 10.4418 & 10.0091 \\
\hline$r<=1 \quad r=2$ & 0.82535 & 0.57401 & 0.28520 & 0.14119 \\
\hline & & & & \\
\hline Trace Tests & & & & \\
\hline$r=0 \quad r=1$ & 40.8695 & 114.0175 & 107.2836 & 103.4876 \\
\hline$r<=1 \quad r=2$ & 28.9857 & 68.2997 & 63.5563 & 60.8367 \\
\hline Eigen Value Tests & & & & \\
\hline$r=0 \quad r>=1$ & 69.8552 & 182.3171 & 170.8399 & 164.3243 \\
\hline$r<=1 \quad r=2$ & 28.9857 & 68.2997 & 63.5563 & 60.8367 \\
\hline & & The & pines & \\
\hline Trace Tests & & & & \\
\hline$r=0 \quad r=1$ & 5.6555 & 4.6936 & 4.5456 & 4.5979 \\
\hline$r<=1 \quad r=2$ & 3.9401 & 3.1240 & 1.6522 & 0.82476 \\
\hline Eigen Value Tests & & & & \\
\hline$r=0 \quad r>=1$ & 9.5956 & 7.8176 & 6.1978 & 5.4226 \\
\hline$r<=1 \quad r=2$ & 3.9401 & 3.1240 & 1.6522 & 0.82476 \\
\hline & & & & \\
\hline$\overline{\text { Trace Tests }}$ & & & & \\
\hline$r=0 \quad r=1$ & 11.6781 & 10.8127 & 10.1070 & 10.0213 \\
\hline$r<=1 \quad r=2$ & 1.4509 & 1.2188 & 0.89281 & 0.61278 \\
\hline Eigen Value Tests & & & & \\
\hline$r=0 \quad r>=1$ & 13.1290 & 12.0316 & 10.9998 & 10.6341 \\
\hline$r<=1 \quad r=2$ & 1.4509 & 1.2188 & 0.89281 & 0.61278 \\
\hline $90 \%$ critical value & 13.8100 & 7.5300 & 17.8800 & 7.5300 \\
\hline & 13.8100 & 7.5300 & 17.8800 & 7.5300 \\
\hline & 12.9800 & 6.5000 & 15.7500 & 6.5000 \\
\hline
\end{tabular}


The null hypothesis of no cointegration, i.e. $\mathrm{r}=0$ can not be rejected at 10 per cent level of significance for countries like India, Turkey, Korea \& The Philippines, while for Pakistan, both trace and Eigen value statistics reveal that $r=0$ and $r \leq$ have been rejected against $r=1$ and $r=2$. These imply the absence of cointegration among IIPs and crude prices.

Consequently the bivariate system of the first difference series, which defines the growth of the respective variable, can be modeled as an unrestricted VAR.

On the basis of Schwarz Bayesian (SBC) and adjusted log-likelihood ratio (LR) Test Criteria, the optimal lag order of the VAR is chosen as 1 in all the cases. The absence of residual serial correlation of the individual equations has also confirmed the correct order of VAR selection.

Finally, the Granger-causality test has been examined as shown in Table 3 below.

Table 3 - Granger Causality Tests

\begin{tabular}{|c|c|c|c|}
\hline Null Hypothesis & $\operatorname{Chi}-\operatorname{Sq}\left(\chi^{2}\right)$ & DOF* & $\mathbf{P}$-value ${ }^{* *}$ \\
\hline Non-causality DX $(\mathrm{T}) \rightarrow \mathrm{DP}(\mathrm{S})$ & 0.11960 & 1 & 0.729 \\
\hline Non-causality $\mathrm{DP}(\mathrm{S}) \rightarrow \mathrm{DX}(\mathrm{T})$ & 2.1714 & 1 & 0.14 \\
\hline Non-causality DX (T) $\rightarrow$ DP (3) & 0.26396 & 1 & 0.607 \\
\hline Non-causality DP $(3) \rightarrow \mathrm{DX}(\mathrm{T})$ & 2.7811 & 1 & 0.095 \\
\hline Non-causality DX $(\mathrm{T}) \rightarrow \mathrm{DP}(6)$ & 0.71592 & 1 & 0.397 \\
\hline Non-causality DP $(6) \rightarrow$ DX $(\mathrm{T})$ & 3.3267 & 1 & 0.068 \\
\hline Non-causality DX (T) $\rightarrow$ DP (9) & 0.72249 & 1 & 0.395 \\
\hline Non-causality DP (9) $\rightarrow$ DX $(\mathrm{T})$ & 3.8371 & 1 & 0.050 \\
\hline Non-causality DX $(\mathrm{I}) \rightarrow \mathrm{DP}(\mathrm{S})$ & 0.013527 & 1 & 0.907 \\
\hline Non-causality DP(S) $\rightarrow$ DX (I) & 2.1243 & 1 & 0.145 \\
\hline Non-causality DX (I) $\rightarrow$ DP (3) & 0.053898 & 1 & 0.816 \\
\hline Non-causality DP (3) $\rightarrow$ DX (I) & 3.1397 & 1 & 0.076 \\
\hline Non-causality DX (I) $\rightarrow$ DP $(6)$ & 0.094600 & 1 & 0.758 \\
\hline Non-causality DP (6) $\rightarrow$ DX (I) & 4.3374 & 1 & 0.037 \\
\hline Non-causality DX (I) $\rightarrow$ DP (9) & 0.19388 & 1 & 0.660 \\
\hline Non-causality DP (9) $\rightarrow$ DX (I) & 3.7390 & 1 & 0.053 \\
\hline Non-causality DX $(\mathrm{Pa}) \rightarrow \mathrm{DP}(\mathrm{S})$ & 0.035733 & 1 & 0.850 \\
\hline Non-causality $\mathrm{DP}(\mathrm{S}) \rightarrow \mathrm{DX}(\mathrm{Pa})$ & 6.5387 & 1 & 0.011 \\
\hline Non-causality DX $(\mathrm{Pa}) \rightarrow \mathrm{DP}(3)$ & 0.31386 & 1 & 0.575 \\
\hline Non-causality DP (3) $\rightarrow$ DX (Pa) & 6.6246 & 1 & 0.010 \\
\hline Non-causality DX $(\mathrm{Pa}) \rightarrow \mathrm{DP}(6)$ & 0.99867 & 1 & 0.318 \\
\hline Non-causality DP $(6) \rightarrow$ DX (Pa) & 6.9575 & 1 & 0.008 \\
\hline Non-causality DX $(\mathrm{Pa}) \rightarrow \mathrm{DP}(9)$ & 1.4645 & 1 & 0.226 \\
\hline Non-causality DP (9) $\rightarrow$ DX (Pa) & 6.4774 & 1 & 0.011 \\
\hline Non-causality DX $(\mathrm{Ph}) \rightarrow \mathrm{DP}(\mathrm{S})$ & 0.061894 & 1 & 0.804 \\
\hline Non-causality DP(S) $\rightarrow$ DX $(\mathrm{Ph})$ & 5.5331 & 1 & 0.019 \\
\hline Non-causality DX $(\mathrm{Ph}) \rightarrow \mathrm{DP}(3)$ & 0.41467 & 1 & 0.520 \\
\hline Non-causality DP (3) $\rightarrow \mathrm{DX}(\mathrm{Ph})$ & 5.4272 & 1 & 0.020 \\
\hline Non-causality DX $(\mathrm{Ph}) \rightarrow \mathrm{DP}(6)$ & 0.51343 & 1 & 0.474 \\
\hline Non-causality DP $(6) \rightarrow$ DX $(\mathrm{Ph})$ & 4.6975 & 1 & 0.030 \\
\hline Non-causality DX $(\mathrm{Ph}) \rightarrow \mathrm{DP}(9)$ & 0.51438 & 1 & 0.473 \\
\hline Non-causality DP (9) $\rightarrow$ DX (Ph) & 4.0745 & 1 & 0.044 \\
\hline Non-causality DX $(\mathrm{K}) \rightarrow \mathrm{DP}(\mathrm{S})$ & 0.43700 & 1 & 0.509 \\
\hline Non-causality DP(S) $\rightarrow$ DX $(\mathrm{K})$ & 0.26541 & 1 & 0.606 \\
\hline Non-causality DX (K) $\rightarrow$ DP (3) & 0.11828 & 1 & 0.73 \\
\hline Non-causality DP (3) $\rightarrow$ DX (K) & 0.13150 & 1 & 0.717 \\
\hline Non-causality DX $(\mathrm{K}) \rightarrow \mathrm{DP}(6)$ & 0.11905 & 1 & 0.730 \\
\hline Non-causality DP (6) $\rightarrow$ DX (K) & 0.085795 & 1 & 0.770 \\
\hline Non-causality DX $(\mathrm{K}) \rightarrow \mathrm{DP}(9)$ & 0.0077805 & 1 & 0.930 \\
\hline Non-causality DP (9) $\rightarrow$ DX (K) & 0.0087122 & 1 & 0.926 \\
\hline
\end{tabular}


The results could be summarized as follows:

- $\quad$ Korea: Non causality among economic growth and prices (spot, $\mathrm{n}=3,6,9)$

- $\quad$ The Philippines: Unidirectional causality from prices to economic growth

- $\quad$ Pakistan: Unidirectional causality from prices to economic growth

- India: Non causality between economic growth and spot price, unidirectional causality from prices $(\mathrm{n}=3,6$, 9) to economic growth

- Turkey: non causality between economic growth and spot price and economic growth and price $\mathrm{n}=3$, unidirectional causality from prices $(n=6,9)$ to economic growth

\section{CONCLUSION}

The study finds the absence of cointegrating relationship between oil prices and economic activity in a bivariate vector auto-regression framework, which suggests that the impact of oil shocks is limited to the short-run for the countries of India, Pakistan, Korea, The Philippines and Turkey.

When analyzing short-run relationships between oil prices and economic growth rates, our empirical results show that a unidirectional causation runs from 6 and 9 month futures prices of oil to economic growth in four of the five countries included in our sample. Furthermore, in the case of The Philippines, Pakistan, and India, our study shows that the higher oil vulnerability of a country results in wider unidirectional causation that includes spot price of oil and 3 month futures price (see Table 4). In addition, higher oil dependency and higher net oil exports (Absolute value) of a country cause similar results.

Table 4: Oil Vulnerability, Dependency and Net Oil Export /GDP

\begin{tabular}{|c|c|c|c|}
\hline Country & Oil Vulnerability & Oil Dependency & $\begin{array}{c}\text { Net Oil Exports } \\
\text { as \% of GDP }\end{array}$ \\
\hline Korea Republic & 1.00 & 0.579 & -3.50 \\
\hline The Philippines & 0.98 & 0.596 & -3.80 \\
\hline Pakistan & 0.83 & 0.425 & -4.40 \\
\hline India & 0.64 & 0.321 & -3.30 \\
\hline Turkey & 0.92 & 0.416 & -2.40 \\
\hline
\end{tabular}

Source: The Impact of Higher Oil Prices on Low Income Countries and on the Poor (March 2005) UNDP/ESMAP (United Nation Development Program/ World Bank Energy Sector Management Assistant Programme).

(1) Oil Vulnerability $=$ Oil consumption - Oil Production Oil Consumption

(2) Oil Dependency = Oil Consumption Total Primary Energy Consumption

Results of our study are very interesting in that they show that producers in our sample countries seem to rely more on oil futures prices in forming their future production decisions than on oil spot prices. This is not to suggest that they do not include other variables in forming their expectations about future oil prices, such as political stability in oil producing countries and expert opinions about futures level of oil prices. However, it may suggest that oil futures prices will have a greater role to play in our economy as these markets mature and or as oil prices continue to increase.

\section{ACKNOWLEDGEMENTS}

Salah Abosedra is grateful to Lebanese American University for funding the project. 


\section{REFERENCES}

1. Abosedra, S. and Baghestani, H. (2004) on the predictive accuracy of crude oil futures prices, Energy Policy, 32, 1389-1393.

2. Asafu-Adjaye, J. (2000) The relationships between energy consumption, energy prices and economic growth: time series evidence from Asian developing countries. Energy Econ, 22, 615-625.

3. Bopp, A.E. and Lady, G.M. (1991) A comparison of petroleum futures versus spot prices as predictors of prices in the future, Energy Economics, 13, 274-282.

4. Bruno, M. and Sachs, J. (1981) Supply versus demand approaches to the problem of stagflation, Macroeconomic Policies for Growth and Stability (Kiel: Institute für Weltwirtschaft).

5. Bruno, M. and Sachs, J. (1982) Input price shocks and the slowdown in economic growth: The case of UK Manufacturing, Review of Economic Studies, 49, 679-706.

6. Burbidge, J. and Harrison, A. (1984) Testing for the effects of oil-price rises using vector autoregressions, International Economic Review, 25, 459-84.

7. Darby, M. (1982) The price of and world inflation and recession, American Economic Review, 72, 738-51.

8. Gisser, M. and Goodwin, T. (1986) Crude oil and the macroeconomy: Tests of some popular nations, Journal of Money, Credit and Banking, 18, 95-103.

9. Gulen, S.G. (1998) Efficiency in the crude oil futures market, Journal of Energy Finance and Development, 3, 13-21.

10. Hamilton, J. (1983) Oil and the macroeconomy since World War II, Journal of Political Economy, 91, 22848.

11. Hamilton, J. (1996) This is what happened to the oil price - macroeconomy relationship, Journal of Monetary Economics, 38, 215-20.

12. Hamilton, J. (2003) What is an oil shock? Journal of econometrics, 113, 363-98.

13. Harkness, J. (1982) Intermediate imports, expectations, and stochastic equilibrium under flexible exchange rates. Canadian Journal of Economics, 15, 118-143.

14. Hwang, D. and Gum, B. (1992) The causal relationship between energy and GNP: The case of Taiwan, Journal of Energy and Development, 16, 219-226.

15. Jiménez-Rodriguez, R. (2004) Oil price shocks: Testing for non-linearity, Center for Studies in Economics and Finance working Paper No. 115.

16. Jiménez-Rodriguez, R. and Sánchez, M. (2005) Oil price shocks and real GDP growth: empirical evidence for some OECD countries, Applied Economics, 37, 201-228.

17. Lee, K., Ni, S. and Ratti, R. (1995) Oil shock and the macroeconomy: The role of price variability, Energy Journal, 16, 39-56.

18. Moosa, I.A. and Loughani, N.E. (1994) Unbiased and time varying risk premia in the crude oil futures market, Energy Economics, 16, 99-105.

19. Mork, K. A. and Hall, R. E. (1980) Energy prices, inflation and recession, 1974-1975, The Energy Journal, 1, 41-53.

20. Mork, K. (1989) Oil shocks and the macroeconomy when prices go up and down: an extension of Hamilton's results, Journal of political Economy, 97, 740-4.

21. Mork, K. (1994) Business cycle and the oil market. Energy Journal, 15, 15-38.

22. OECD Economic Outlook No. 76

23. Peroni, E. and McNown, R. (1998) Noinformative and informative tests of efficiency in three energy future market. The journal of future market, 18, 939-64.

24. Quan, J. (1992) Two-step testing procedure for price discovery role of futures prices, The Journal of Futures Markets, 12, 139-149.

25. UNDP/ESMAP (United Nations Development program/World Bank Energy Sector Management Assistance Programme), The impact of higher oil prices on low income countries and on the poor, March 2005.

26. Yang, H. (2000). A note on the causal relationship between energy and GDP in Taiwan, Energy Economics, 22, 309-317. 